\title{
Perspective Directions of Optimization of the Phytosanitary State by Industrial Plantations of Sea Buckthorn
}

\author{
Shamanskaya Lyubov Demyanovna \\ M.A. Lisavenko research institute of horticulture for Siberia (FSBSI), Plant Protection, Barnaul, Zmeinogorsky tract, 49, 656045, \\ Russia
}

\begin{abstract}
Are treated the main directions of optimization of phytosanitary condition of industrial plants sea buck thorn that reduce the pesticide load in the sea buckthorn censes by growing resistant varieties, the development of short-term forecast of the number of main pest - sea buckthorn fly, the introduction of the biological method of protection of sea buckthorn from damaging fauna and reducing of norm consumption to pesticide chemistry Aktellik and biogenetic preparation Fitoverm when they used in conjunction with the biosupplements. Biosupplements reduces norm consumption Fitoverm of 2 times, Aktellik to 2.4 times, contributes to a better development of the plant, provides increased yields and improve the quality of the fruit on the basic parameters: the content of carotenoids and the oil, reduces the quantity of pesticide to 4 times, and in some cases produces no toxic residues crop.
\end{abstract}

Key words: Sea buckthorn, pests, preparations, biosupplement, efficiency.

\section{Introduction}

Sea buckthorn is the main crop in the commercial horticulture in Siberia. Due to the high ecological plasticity and rich composition of the fruit it began to grow in many countries.

Following sea buckthorn learn new habitats pests, among which Sand thorn fly (Rhagoletis batava obscuriosa Kol.) is the most malicious object. «Sand thorn fly spread rapidly in Eastern Europe, which currently has an economic value in the production of sea buckthorn» [1-3].

The ubiquity and high losses from sea buckthorn fly in central Russia were the main cause of failure of the cultivation of sea buckthorn in the region. In the Altai region, where the main industrial plantation of sea buckthorn, yield losses from this pest reaches $100 \%$.

The development of measures to combat sea buckthorn fly in the Altai was launched in 1960 and

Corresponding author: Shamanskaya Lyubov Demyanovna, scientist agronomist, professor, research field: plant protection. continues to this day. «Many years of practice to combat sea buckthorn fly showed that the crop protection chemical pesticides ensure that does not guarantee a product without any toxic residues» [4].

This problem can be successfully solved by growing resistant varieties. When the multi-year assessment of the Altai sea buckthorn varieties genotype allocated 1 sustainable form and 14 forms relatively resistant to sea buckthorn fly. However, their cultivation does not allow to fully solving the problem of pest control as $55 \%$ of the recognized varieties are highly susceptible to sea buckthorn fly.

Long-term observations have shown that the number of fly varies considerably from year to year and is more dependent on a biotic factor. In this regard, especially important to forecast the number of pests.

We have developed a short-term forecast of the number of sea buckthorn fly, allowing in some years to abolish chemical treatments on dozens of hectares of industrial plantations of sea buckthorn and get ecologically clean products. Only in the last 3 years 
(2014-2016), chemical treatments have been canceled on the area of 314 hectares, which corresponds to $80 \%$ of the total area of industrial plantations FSBSI. In this economy only means of protection were 740 thousands rubles.

Production of ecologically clean products, and possibly through the use by method of biological protection crop. «However, attempts to replace chemical pesticides biological protection» $[5,6]$, «including a classical biological control» $[7,8]$ is not widely used in practice.

Our research has shown promising use against sea buckthorn fly biological preparation Fitoverm developed on the basis of natural toxins in the SBC Farmbiomed [9]. However Fitoverm expensive preparation and it is a major obstacle to its wide application in practice.

The aim of our research - to develop ways to optimize phytosanitary condition of industrial plants sea buckthorn.

\section{Condition, Materials and Research Methods}

Evaluation of varieties and hybrid fund sea buckthorn breeding FSBSI susceptibility to sea buckthorn fly conducted visually on the background of the lack of treatments.

Observations of the cycle of sea buckthorn fly and test drugs against the pest were carried out on a stationary site in 2011-2014 years, on varieties of Chujskaja and Elizabeth. The expected loss of harvest is determined by the original method [9].

The hot and dry summer of 2011, with a maximum air temperature $26.0-30.5^{\circ} \mathrm{C}$ contributed actively and resettlement of sea buckthorn fly with an old plantation on a stationary portion, resulting in the loss of the harvest in the year of entry into fruiting plants was $100 \%$. In 2012, the summer was hot and dry with maximum temperature of $27.5-33.5{ }^{\circ} \mathrm{C}$, on $4.8{ }^{\circ} \mathrm{C}$ above normal, with precipitation $69.9 \%$ of the norm. Under these conditions, a marked decrease in the number of sea buckthorn flies with the expected loss of crop varieties by Chujskaja and Elizabeth at $34-40 \%$. In 2013, due to the long and cool spring, it marked the beginning of the summer later adult insects, which are not reflected in their numbers. The expected loss of harvest was $100 \%$. Abnormal heat (up to $38{ }^{\circ} \mathrm{C}$ ) during the laying of eggs and development in 2014, has caused mass mortality and contributed to a significant reduction in severity sea buckthorn fly. As a result, the actual loss of crop varieties by Chujskaja and Elizabeth was $19 \%$ and $30 \%$.

Testing preparations against sea buckthorn fly was conducted in small practices, on the background a single (Aktellik) and double (Fitoverm) spraying. Plants treated with knapsack sprayer by «Kwazar» norm 0.6-2 liters depending on their age. Control plants were not treated. Repeated experience 3 fold, 5-7 plants per repetition. Accommodation plots consistently. The total area of the experimental plot 0.7 hectares. Besides the main pest—sea buckthorn fly, the pilot area have been observed related malicious objects: Gelechia hippophaeella Schak. and ticks: Aceria hippophaenus Nal. Vasathes tibialis Liro., which greatly inhibit the growth and development plants. The high number of these pests has been noted in 2011, in the period of entry into bearing buckthorn. In 2012, drought conditions, the number of Gelechia hippophaeella was moderate, Vasathes tibialis-high. Hot and dry weather in 2012 contributed to the mass death of Aceria hippophaenus. Special protective measures against these pests in the experimental area were not carried out. Their deaths are recorded on the background of treatment against sea buckthorn fly.

The effectiveness of drugs against these pests was determined by the method of Gar K.A. [10].

Accounting for harvest was carried out on the sort of Chujskaja, on 2 plants each repetition model.

Biochemical analysis on fruit varieties Chujskaja and Elizabeth was conducted in biochemistry laboratory FSBSI by conventional means. 
Toxicological tests on fruits background Aktellik processing on the background by gas-liquid chromatography in the Central Scientific-production veterinary radiology laboratory of (city Barnaul). Remains Aversectin- $\mathrm{C}$, the active ingredient of the preparation of Fitoverm was determined in SBC "Farmbiomed" by high gas-liquid chromatography (city Moscow).

Experimental data processed by analysis of variance [11].

\section{Results of Research and Discussion Норма Расхода биологически актив ной}

Preliminary exploratory experiments have showed the possibility of reducing the consumption rate Fitoverm and Aktellik from their use in combination with biologically active supplement. For develop biosupplements we used the components similar in structure and properties of the substances contained in the plants themselves. It was revealed that the supplement reduces Fitoverm reduce by 2 times, Aktellik 2.4 times. Later the effectiveness of these drugs has been tested in long-term stationary against a complex of pests.
For 4 years Fitoverm and Aktellik in conjunction with biosupplements showed steady performance result, ensuring the death of the larvae of sea buckthorn flies to $98.1-100 \%$, i.e. at the level of effectiveness of preparations in the total dosage (Table 1).

The effectiveness of preparations in full and reduced dosages against caterpillars of Gelechia hippophaeella was 95.1-100\% (Table 2).

The high acaricidal activity showed Fitoverm by full and reduced dosage, ensuring the death of mites at 94.4-99.4\%.

A significant reduction in severity of mites and Gelechia hippophaeella contributed to a better development of the plant, especially in the treatment of backgrounds, including the biosupplements, which includes a growth factor. The difference in the development of plants affected sea buckthorn yield in 2012-2014. The highest productivity for a total of 3 years 21.48-22.92 tons/hectare has received by the spraying Aktellik and Fitoverm in conjunction with the biosupplements, which substantially exceeds the rate at preparations treatment in its purest form. The productivity increase in the first case amounted to $157-167 \%$, in the second $148-155 \%$ (Table 3).

Table 1 The effectiveness of preparations against sea buckthorn fly.

\begin{tabular}{llllll}
\hline \multirow{2}{*}{ Option } & \multicolumn{5}{c}{ The death of larvaes (\%) } \\
\cline { 2 - 6 } & 2011 г. & 2012 г. & 2013 г. & 2014 г. & Average for 2011-2014 \\
\hline Without treatment-control & 0.1 & 2.4 & 5.9 & 5.5 & 3.5 \\
Aktellik-0.1\% & 100 & 100 & 100 & 100 & 100 \\
Aktellik-0.04\%+ biosupplements & 100 & 100 & 100 & 100 & 100 \\
Fitoverm-0.3\% & 96.4 & 96.8 & 97.0 & 100 & 97.6 \\
Fitoverm-0.15\% + biosupplements & 97.5 & 96.3 & 99.1 & 99.3 & 98.1 \\
The least significant difference of 0.5 for the factors & 1.2 & 0.8 & 1.8 & 1.4 & 5.7 \\
\hline
\end{tabular}

Table 2 The effectiveness of preparations against Gelechia hippophaeella and mites. The average for 2011-2012.

\begin{tabular}{|c|c|c|c|}
\hline \multirow{3}{*}{ Option } & \multicolumn{3}{|l|}{ The death $(\%)$} \\
\hline & \multirow{2}{*}{$\begin{array}{l}\text { Gelechia } \\
\text { hippophaeella }\end{array}$} & \multicolumn{2}{|c|}{ Mites } \\
\hline & & Aceria hippophaenus & Vasathes tibialis \\
\hline Without treatment - control & 13.0 & 6.5 & 7.6 \\
\hline Aktellik- $0.1 \%$ (reference) & 97.9 & 74.6 & 78.1 \\
\hline Aktellik- $0.04 \%+$ biosupplements & 100 & 77.0 & 61.4 \\
\hline Fitoverm- $-0.3 \%$ & 100 & 98.9 & 94.4 \\
\hline Fitoverm- $-0.15 \%+$ biosupplements & 95.1 & 97.2 & 99.4 \\
\hline The least significant difference of 0.5 for the factors & 4.8 & 2.6 & 13.4 \\
\hline
\end{tabular}


Table 3 Yield buckthorn on different backgrounds processing. Sort Chujskaja, planting autumn 2008.

\begin{tabular}{|c|c|c|c|c|c|}
\hline \multirow{2}{*}{ Option } & \multicolumn{4}{|c|}{ Productivity tons/hectare } & \multirow{2}{*}{$\begin{array}{l}\text { Increase to } \\
\text { control }(\%)\end{array}$} \\
\hline & 2012 & 2013 & 2014 & The amount in 3 years & \\
\hline Without treatment - control & 1.80 & 0.15 & 11.75 & 13.70 & - \\
\hline Aktellik— $0.1 \%$ (reference) & 3.85 & 1.94 & 14.50 & 20.29 & 148 \\
\hline Aktellik- $0.04 \%+$ biosupplements & 4.52 & 1.96 & 15.0 & 21.48 & 157 \\
\hline Fitoverm Фитоверм—0.3\% & 3.20 & 1.70 & 16.30 & 21.20 & 155 \\
\hline Fitoverm- $-0.15 \%+$ biosupplements & 4.30 & 1.87 & 16.75 & 22.92 & 167 \\
\hline The least significant difference of 0.5 for the factors & 0.98 & 0.07 & 0.27 & 0.70 & - \\
\hline
\end{tabular}

Thus, a dietary supplement can not only reduce the rate of drug consumption, but also helps to ensure a higher yield due to better plant growth.

Biologically activity supplement contributed to a statistically significant increase in fruit weight in the dry 2012, which is based on 100 fruits accounted for a sort Chujskaja $53.1 \mathrm{~g}$ (in conjunction with Aktellik) and $54.5 \mathrm{~g}$ (in conjunction with Fitoverm) against 50.0-51.4 $\mathrm{g}$ at preparations used in the full dosage.

In 2012, the production was carried out verification of the effectiveness of low dose Aktellik against sea buckthorn fly on area 28 hectare. The treatment was carried out from a tractor-sprayer Sp-2000 with cconsumption rate of the preparation 1 liter/hectare. The effectiveness of treatment for a variety of grades and quarters was $100 \%$ (Table 4 ).

The results of biochemical analysis for a variety of fruits Chujskaja testify in small plots option experience that the main indicators of the content of carotenoids and oil fluctuated significantly from year to year and made the control 15.8-17.4 $\mathrm{mg} \%$ and 3.71-5.48 mg\%, respectively (Table 5).

When processing Aktellik combined with biosupplements, 3 years carotenoid content on average was higher than when using the full dosage of preparations and was respectively 19.4 and $15.6 \mathrm{mg} \%$. By the treatment Fitoverm in combination with biosupplements carotenoid content was $16.8 \mathrm{mg} / \%$ against $17.5 \mathrm{mg} / \%$ by the full dose of the preparation. The maximum oil content of $4.80 \%$ and $4.88 \%$ obtained in options of treatment Aktellik and Fitoverm in conjunction with the biosupplements. Biochemical analysis for a variety of fruits by sort Elizabeth also showed a tendency to increase the content of carotenoids and the oil during by spraying Aktellik and Fitoverm in complex with the biosupplements.

In the production experience for a variety Chujskaja on the background Aktellik processing in complex with biosupplements, compared with a full dose of the preparation, the amount of carotenoids increased from $17.9 \mathrm{mg} \%$ to $20.1 \mathrm{mg} \%$, the oil with $4.91 \%$ to $5.64 \%$.

Fruit toxicological analysis showed a significant difference in residues perimifos-methyl (active ingredient Aktellik) on dates: from $0.310 \mathrm{mg} / \mathrm{kg}$ to $0.400 \mathrm{mg} / \mathrm{kg}$ by total dose Aktellik and from $0.077 \mathrm{mg} / \mathrm{kg}$ to 0.188 $\mathrm{mg} / \mathrm{kg}$ by the reduced dosage (Table 6 ).

The most active aktellik decomposition was observed in the dry 2012. This year, in small plot experiment the amount of toxic residues in the fruit on the background of treatment reduced dose of Aktellik decreased to 4 times if to compare with the full dose of the preparation. On average over 3 years amount residues of pesticide on this backdrop the processing has decreased to 2.5 times. In production testing reduced doses Aktellik toxic residues in the fruit of sea buckthorn are not detected.

Toxicological analysis of the fruit thrice held in SBC "Farmbiomed" on the background of spraying Fitoverm showed a complete absence of residues of the preparation to the beginning of the harvest.

Calculation of economic efficiency showed a significant change in the level of profitability of the production of the fruit for years. In 2012, the second year of the entry into fruiting plants, the figure was in the control $48 \%$, in different backgrounds processing $33-72 \%$ (Table 7). 
Table 4 Efficiency Aktellik in conjunction with biosupplements against sea buckthorn fly. Production processing.

\begin{tabular}{lllll}
\hline Quarter & Sort & $\begin{array}{l}\text { The expected loss of } \\
\text { harvest, \% }\end{array}$ & $\begin{array}{l}\text { Consumption rate of } \\
\text { Aktellik, liter/hectare }\end{array}$ & The death of larvaes (\%) \\
\hline 4 & Chujskaja & 13,9 & 1 & 100 \\
1 & Chujskaja & 21,0 & 0,5 & 100 \\
2 & Chujskaja & 14,0 & 0,5 & 100 \\
12 & Elizabeth & 16,0 & 0,5 & 100 \\
24 & Altajskaja & 17,2 & 0,5 & 100 \\
\hline
\end{tabular}

Table 5 The biochemical composition of fruits on different backgrounds processing. Sort Chujskaja.

\begin{tabular}{|c|c|c|c|c|c|c|c|c|}
\hline \multirow{2}{*}{ Option } & \multicolumn{4}{|c|}{ The amount of carotenoids $(\mathrm{mg} / \%)$} & \multicolumn{4}{|c|}{ Crude oil weight (\%) } \\
\hline & 2012 & 2013 & 2014 & Average & 2012 & 2013 & 2014 & Average \\
\hline Without treatment - control & 17.3 & 15.8 & 17.4 & 16.8 & 5.48 & 3.75 & 3.71 & 4.31 \\
\hline Aktellik- $0.1 \%$ (reference) & 14.0 & 17.5 & 45.3 & 15.6 & 5.66 & 4.16 & 4.56 & 4.79 \\
\hline Aktellik- $0.04 \%+$ biosupplements & 20.1 & 17.5 & 20.7 & 19.4 & 5.61 & 4.13 & 4.91 & 4.80 \\
\hline Fitoverm- $-0.3 \%$ & 17.4 & 18.3 & 16.8 & 17.5 & 5.85 & 3.66 & 4.38 & 4.63 \\
\hline Fitoverm- $-0.15 \%+$ biosupplements & 15.9 & 16.8 & 17.6 & 16.8 & 5.45 & 4.52 & 4.67 & 4.88 \\
\hline \multicolumn{9}{|l|}{ Production experience } \\
\hline Aktellik-0.1\% & 17.9 & - & - & - & 4.91 & - & - & - \\
\hline Aktellik- $0.05 \%+$ biosupplements & 20.1 & - & - & - & 5.64 & - & - & - \\
\hline
\end{tabular}

Table 6 Amount of residues perimifos-methyl on different backgrounds processing.

\begin{tabular}{lllll}
\hline \multirow{2}{*}{ Option } & \multicolumn{3}{c}{ Residues perimifos-methyl (mg/kg) } \\
\cline { 2 - 5 } & 2012 & 2013 & 2014 & Average to 2012-2014 \\
\hline Aktellik-0.1\% (reference) & 0.310 & 0.383 & 0.400 & 0.364 \\
Aktellik-0.04\% + biosupplements & 0.077 & 0.172 & 0.188 & 0.145 \\
\hline
\end{tabular}

Table 7 Cost-effectiveness of the production of fruits in different backgrounds processing. Sort Chujskaja.

\begin{tabular}{|c|c|c|c|c|c|c|c|}
\hline \multirow{2}{*}{ Option } & \multicolumn{3}{|c|}{ Yield, tonnes/hectare } & \multicolumn{4}{|c|}{ The level of profitability (\%) } \\
\hline & 2012 & 2013 & 2014 & 2012 & 2013 & 2014 & Average \\
\hline Without treatment-control & 1.80 & 0.15 & 11.7 & 48 & 2 & 161 & 70 \\
\hline Aktellik_-1 liter/ha (reference) & 3.85 & 1.94 & 14.5 & 61 & 27 & 186 & 91 \\
\hline Aktellik— -0.4 liter/ha + biosupplements & 4.52 & 1.96 & 15.0 & 72 & 38 & 188 & 99 \\
\hline Fitoverm-6 liter/ha & 3.20 & 1.70 & 16.3 & 33 & 3 & 185 & 74 \\
\hline Fitoverm-3 liter/ha + biosupplements & 4.30 & 1.87 & 16.7 & 63 & 5 & 191 & 86 \\
\hline
\end{tabular}

The maximum level of profitability of $86-99 \%$ is obtained by treatment sea buckthorn from reduced dose Fitoverm and Aktellik in conjunction with biosupplements. By treatment in full and a reduced dosage of Fitoverm profitability fruit production compiled $74-86 \%$ on average over 3 years. A significant decrease of this indicator in the backgrounds processing Fitoverm observed in 2013. due to the low productivity of seabuckthorn.

\section{Conclusions}

Thus, the perspective directions of optimization of phytosanitary condition of industrial plants sea buckthorn are: cultivation of varieties resistant and relatively resistant to sea buckthorn fly, the development of short-term forecast of the number of 
pests, biological defense from parasitic fauna, the application rates reduction of chemical and biogenic preparations.

Ecology appropriate and economically viable to use for the protection of sea buckthorn from the complex from pests biogenic preparation Fitoverm in combination with biosupplement, that to reduces the rate of its in 2 times. Biosupplement contributes to a better development of the plant, provides for maximum harvest and improve the quality of the fruit on the main indicators - the content of carotenoids and oil.

\section{Reference}

[1] Hohne, F. 2014. "Monitoring sea buckthorn fly in Mecklenburg-Vorpommern on 2014.” Producing Quality Sea Buckthorn. Naantali, Finland.

[2] Shalkevich, M. 2012. "Seabuckthorn Cultivars Resistance to Rhagoletis batava var. obscuriosa Kol. in Belarus." The 2nd european workshop on seabuckthorn. Program, EuroWorks 2012 Integrated forestry development project. Integrated Pest management plan.

[3] Stalazc, A. 2014. "Review of sea buckthorn pests in Latvia” Producing Quality Sea Buckthorn. Naantali, Finland.
[4] Goreeva, T. S., and Prokof'ev, A. M. 1996. "Problems of protection of plants against pests and diseases in the gardens of Siberia." Scientific bases Siberian gardening. Novosibirsk.

[5] Kal'vish, T. K., Sanzhimitupova, R. D., Sharapov, V. M., and Hodyrev, V. P. 1986. "Microbiological plant protection products." Novosibirsk.

[6] Hovalyg, N. A. 2005. Pests of sea buckthorn and action to destroy its phytosanitary condition in Tuva. Abstract of dissertation for the degree of Candidate of Agricultural Sciences. Novosibirsk.

[7] Berger, L. P., and Danilov, L. G. 1998. "Prospects for the use of entomopathogenic nematodes against sea buckthorn fly." Abstracts of the 3rd International Symposium on buckthorn. Ulan-Ude.

[8] Danilov, L. G., and Pavljushin, V. A. 2015. "Status and prospects of studying and practical use of entomopathogenic nematodes (Steinernematidae) and their symbiotic bacteria (Xenorhabdus) against insects and plant pathogens." Plant Protection News. N 3 (85): 10-5.

[9] Shamanskaya, L. D., and Usenko, V. I. 2007. A method of estimating the loss of sea buckthorn harvest caused by sea buckthorn fly. RF Patent number 2297135. Prioritet 11.01.05 Published 20.04.2007, Byul. №11.

[10] Gar, K. A. 1963. Methods for testing the toxicity and efficacy of pesticides. M.

[11] Dospehov, B. A. Methods of field experience. M., "Kolos". 